\title{
Possible countergradient variation in growth of juvenile cod Gadus morhua from the northwest Atlantic
}

\author{
Manjusri P. Wijekoon ${ }^{1}$, Velmurugu Puvanendran ${ }^{2, *}$, Danny W. Ings ${ }^{1}$, \\ Joseph A. Brown ${ }^{1, \mathrm{I}}$
}

${ }^{1}$ Ocean Sciences Centre, Memorial University of Newfoundland, St. John's, Newfoundland A1C 5S7, Canada

${ }^{2}$ Nofima, Muninbakken 9-13, 9291 Tromsø, Norway

\begin{abstract}
To test the countergradient variation (CnGV) hypothesis and determine any genetic differences among populations, we conducted an experiment with juvenile cod originating from 3 regions in the NW Atlantic, 3Ps (Placentia Bay, Newfoundland, Canada; $48^{\circ} \mathrm{N}, 54^{\circ} \mathrm{W}$ ), $4 \mathrm{~T}$ (southern Gulf of St. Lawrence; $\left.46^{\circ} \mathrm{N}, 61^{\circ} \mathrm{W}\right)$, and $4 \mathrm{X}\left(44^{\circ} \mathrm{N}, 67^{\circ} \mathrm{W}\right)$, at 2 temperatures $\left(7\right.$ and $\left.11^{\circ} \mathrm{C}\right)$ for $15 \mathrm{wk}$. Results indicated that temperature influenced the growth rates of individuals in all 3 populations, and juveniles reared at $11^{\circ} \mathrm{C}$ were significantly bigger (length and weight) than those reared at $7^{\circ} \mathrm{C}$. No significant differences in growth and food conversion efficiency were found among the 3 populations. Although 3Ps juveniles were significantly smaller in length and lighter in weight than $4 \mathrm{~T}$ and $4 \mathrm{X}$ juveniles at the start of the experiment, length and weight did not differ among populations at the end of the experiment. Survival of both 3Ps and $4 \mathrm{~T}$ juveniles was significantly higher than that of $4 \mathrm{X}$ cod in both high and low water temperature treatments. Although statistical analyses showed no significant differences in growth and food conversion efficiency among juveniles from the 3 populations, reaction norm analysis showed a strong genotypic influence on growth and survival (no genotype $x$ environment interactions) but a genotypic $\times$ environment interaction in food conversion efficiency. Our results suggest that Atlantic cod juveniles from these 3 regions do not show CnGV in growth and food conversion efficiency. However, performance differences among populations may be stage specific, and this may have masked CnGV in traits among Atlantic cod populations in our study.
\end{abstract}

KEY WORDS: Growth $\cdot$ Geographic variation $\cdot$ Survival $\cdot$ Adaptation $\cdot$ Atlantic cod

\section{INTRODUCTION}

Both genetic and environmental parameters influence the characteristics of fish populations. It is difficult to determine which of these 2 factors is operating on widely dispersed populations of fish (Conover \& Present 1990). Countergradient variation (CnGV) of growth in fish is a hypothesis developed by Conover (1990) and Conover \& Present (1990) which predicts that growth and other life history traits in fishes will vary over latitude, with higher latitude populations showing comparatively higher growth performances. Such performance differences across the latitudes may reflect adaptations to the length of the growing season. Several fish species have been shown to exhibit CnGV in growth, including larval striped bass Morone saxatilis (Walbaum), American shad Alosa sapidissima (L.), Atlantic silverside Menidia menidia (L.), and mummichog Fundulus heteroclitus (L.) (Conover 1990, Conover et al. 1997).

Svåsand et al. (1996) and Purchase \& Brown $(2000 a, b)$ discussed the possibility of examining highly selected traits, such as growth rate, using common environment experiments. Such experiments may provide insights into the genetically based phenotypic differences among populations and may further provide 
evidence for intra-specific adaptation. This also allows for tests of patterns in genetic variability, such as CnGV (Conover et al. 1997). There is a large amount of life history variation in Atlantic cod Gadus morhua, with faster growth rates and younger age at maturity generally occurring in warmer water (Brander 1994, Salvanes et al. 2004). Similarly, cod populations can be genetically distinguished across regional scales (i.e. $>100 \mathrm{~km}$; Knutsen et al. 2007), suggesting that there is genetic scope for regional differences in life history traits. However, genetic differentiation based on molecular analyses alone does not provide enough information on phenotypic and life history variations among cod stocks, and also sensitivity of these molecular techniques has been questioned recently due to the variable techniques used (Ruzzante et al. 1999). Thus, correlations between phenotypes and environmental factors may not have a genetic basis, but rather may be based on environmental influences on phenotypes. Furthermore, local environmental conditions can also strengthen, reduce, or even reverse genetically based differences among populations. Thus, experiments subjecting Atlantic cod from different populations to similar environmental conditions could provide more insight on understanding the relative importance of genetic effects, environmental conditions, and genotype and environment interactions for creating variation in phenotypic traits among natural populations (Conover \& Schultz 1995).

Historically, Atlantic cod has been a significant fisheries resource in the North Atlantic Ocean, and considerable effort has been directed toward elucidating the Atlantic cod population structure (Jónsdóttir et al. 2001). Atlantic cod are found from Baffin Island $\left(\sim 63^{\circ} \mathrm{N}\right)$ to Cape Hatteras $\left(\sim 35^{\circ} \mathrm{N}\right)$ along the North American coast in the NW Atlantic (Scott \& Scott 1988). Due to the vast distribution of Atlantic cod, understanding population structure is fundamental to their assessment, conservation, and management. If population structure is not clearly defined, all cod populations will be managed in a similar manner regardless of their differences in biological attributes such as growth and reproductive performances, and such management strategies may be dangerous (Bradbury et al. 2008). However, despite extensive research on cod population structure, the overall results have been controversial and difficult to interpret from a management perspective (Bentzen et al. 1996). Geographic surveys (Hutchings et al. 1993), vertebral data (Templeman 1981), and tag recovery data (Taggart et al. 1995) suggest the existence of several distinct offshore spawning units of northern cod. Further, Bentzen et al. (1996) and Ruzzante et al. (1997) found genetic variation using microsatellite loci when comparing northern cod from inshore bays with those from offshore locations, suggesting that separate stocks exist in the 2 areas. Such studies, while advancing our understanding of gene flow, are, however, ineffective in detecting population differences in phenotypic plasticity for fitnessrelated traits such as growth, survival, and condition factors (Hutchings et al. 2007). Nevertheless, most of the existing quantitative genetics models have also failed to predict the patterns and the strength of selection on traits in different environments. Overall, the patterns and strength of selection on traits in different environments are poorly understood despite abundant evidence of population structure and life history differences in cod. Thus, quantitative predictions for how selection and evolution will be altered by environmental changes are relatively unknown.

Reaction norms have been used to describe how the expected phenotype of a given genotype responds to varying environmental conditions and, thus, is a useful tool for exploring the patterns and strength of selection on traits in different environments (Ricklefs \& Wikelski 2002). In the laboratory, reaction norms (e.g. growth rate) have successfully been used to test CnGV theory in fish populations (Conover \& Schultz 1995). However, in Atlantic cod, studies of CnGV theory have been limited to 2 populations (Svåsand et al. 1996, Otterlei et al. 1999, Purchase \& Brown 2000a,b, Salvanes et al. 2004). Marcil et al. (2006a) showed that laboratory reared juvenile cod from 2 regions of the NW Atlantic, 4X and 3L (Northwest Atlantic Fisheries Organization [NAFO] divisions), differed significantly in their body shape, yet no differences were found between the wild collected juveniles of the same origin. This suggests that phenotypic differences in body shape between the 2 cod populations could have been masked by opposing effects of the environmental differences experienced in the wild. Thus, rearing these 2 cod populations under similar environmental conditions would help to remove these masking effects and to study the genetic basis of reaction norms of putatively different groups (Conover \& Schultz 1995).

Cod populations from NAFO divisions 3Ps (Placentia Bay, Newfoundland, Canada; $48^{\circ} \mathrm{N}, 54^{\circ} \mathrm{W}$ ), and $4 \mathrm{~T}$ (southern Gulf of St. Lawrence; $46^{\circ} \mathrm{N}, 61^{\circ} \mathrm{W}$ ) spawn during spring to early summer (April to June), while cod in the $4 \mathrm{X}$ region (Scotian Shelf; $44^{\circ} \mathrm{N}, 67^{\circ} \mathrm{W}$ ) spawn in winter (late January to March) (Hutchings et al. 1993). Because of the differences in spawning time, larvae and juveniles from these 3 populations experience different temperatures. While cod larvae from $4 \mathrm{X}$ experience colder temperatures, 3Ps and 4T cod larvae are exposed to relatively warm temperatures; the opposite is true for juveniles (Marcil et al. 2006b). Adult populations, however, show seasonal migrations either on a larger $(4 \mathrm{~T})$ or smaller (3Ps and $4 \mathrm{X}$ ) scale (Lawson \& Rose 2000, Comeau et al. 2002). Temperature in 3Ps 
and $4 \mathrm{~T}$ areas is highly variable, with winter temperatures reaching below $0^{\circ} \mathrm{C}$ and summer temperatures reaching $12^{\circ} \mathrm{C}$ at $20 \mathrm{~m}$. Temperatures in the $4 \mathrm{X}$ area range between $2-3^{\circ} \mathrm{C}$ in winter and $10-12^{\circ} \mathrm{C}$ in summer (Marcil 2004). Although summer temperatures are similar in all 3 areas, the growing season is shorter at northern latitudes and, according to $\mathrm{CnGV}$, organisms living at higher latitude show greater intrinsic growth rates to compensate for the shorter growing season (Conover 1990).

In the present study, we examined the effects of temperature on growth rate, survival, and food conversion efficiency (FCE) of Atlantic cod juveniles from 3 latitudinally separated cod populations: $3 \mathrm{Ps}, 4 \mathrm{~T}$, and $4 \mathrm{X}$. To test for overall differences between populations, we performed a repeated measures analysis and used ANOVA to test for differences during shorter time periods (week $\times$ population interactions). Using an analysis of reaction norms, we tested the prediction that cod from higher latitudes would grow faster and display higher FCEs than the cod from lower latitudes (Marcil et al. 2006a, Hutchings et al. 2007, Yamahira et al. 2007).

\section{MATERIALS AND METHODS}

Broodstock. To test for CnGV, we collected adult Atlantic cod from 3 NAFO divisions - 3Ps, 4 T (in 2001), and 4X (2003) - that differed in latitude (Fig. 1). All fish were captured prior to spawning and kept in captivity either at the Joe Brown Aquatic Research Building (JBARB), Ocean Sciences Centre (OSC), Memorial University of Newfoundland, Canada (3Ps), or at Dalhousie University, Halifax, Canada (4T and 4X). The number of adult fish from each division used in the study ranged between 54 and 77 . Fish from 3Ps were brought to the OSC and kept in two $12 \mathrm{~m}^{3}$ tanks. After they were brought to the laboratory, the water temperature was gradually increased from 2 to $6^{\circ} \mathrm{C}$ over $10 \mathrm{~d}$. Initially, they were fed with frozen fish (herring) with vitamin supplementation every $3 \mathrm{~d}$, and gradually weaned onto a commercial dry feed (Surgain Feed, Maple Leaf Foods). Once weaned, the broodstock was fed ad libitum daily. Adult Atlantic cod broodstock from $4 \mathrm{~T}$ and $4 \mathrm{X}$ were kept under conditions similar to those for 3Ps; however, the size of the holding tank for $4 \mathrm{~T}$ and $4 \mathrm{X}$ was $680 \mathrm{~m}^{3}$.

Eggs were collected from the 3 broodstocks to provide juveniles for our experiment. No eggs were collected for incubation until 2 wk after the spawning started, to ensure that better quality eggs were used (Kjesbu et al. 1996). Then, 4 batches of eggs (each batch consisted of eggs spawned over 2 consecutive days) were collected from each population during spontaneous spawning. We adopted this protocol to increase the number of families represented by each population. The number of families representing each population was determined by sampling larvae at hatch and using the microsatellite technique (see

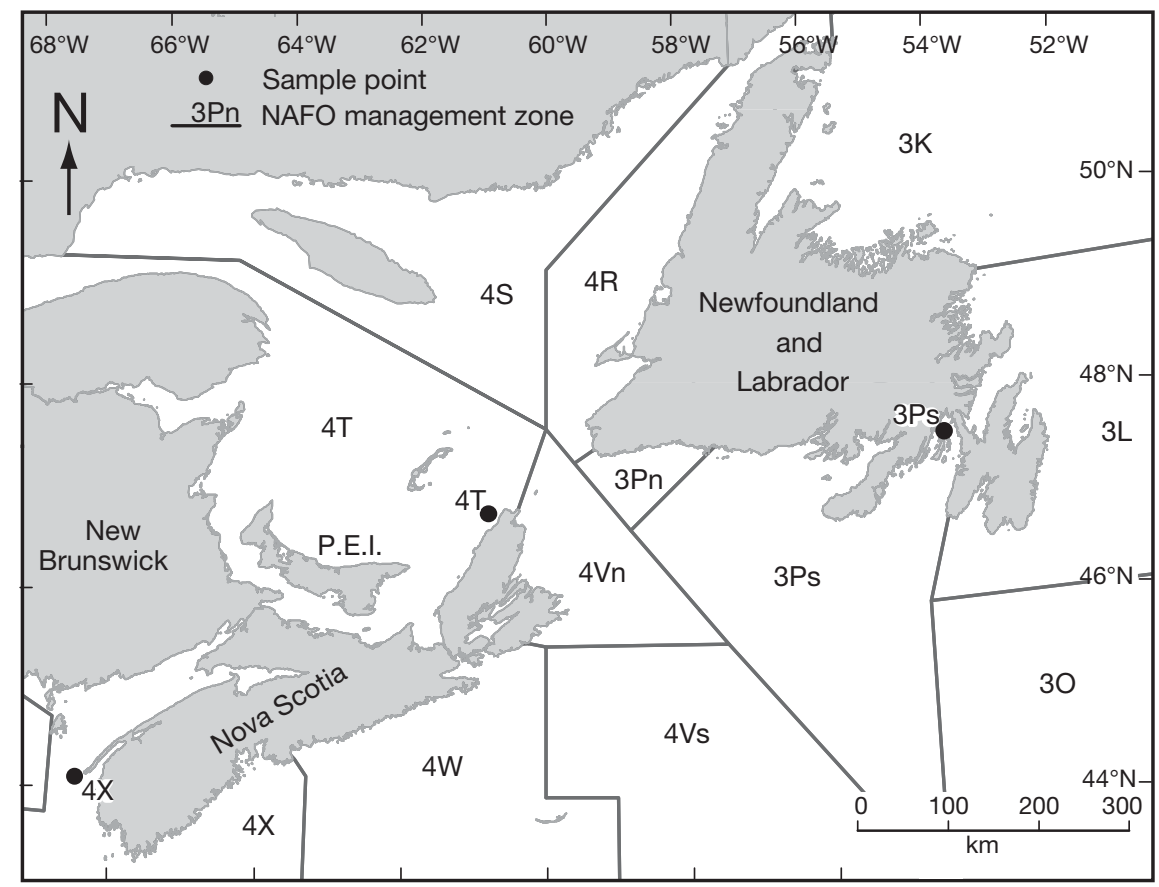

Fig. 1. Adult cod sampling locations in the NAFO division. P.E.I.: Prince Edward Island 
Hutchings et al. 2007 for more details). Results showed that the number of families represented at the end of the experiments for populations 3Ps, 4T, and $4 \mathrm{X}$ was 44,31 , and 21, respectively. For $4 \mathrm{~T}$ and $4 \mathrm{X}$, eggs from 8 consecutive spawnings (4 batches) were transported from Dalhousie University to OSC at 30 to 50 degreedays ( 4 to $6 \mathrm{~d}$ at 6 to $8^{\circ} \mathrm{C}$ ).

Egg incubation and larval rearing. All larval and juvenile rearing was carried out at the JBARB. Fertilized eggs from $3 \mathrm{Ps}, 4 \mathrm{X}$, and $4 \mathrm{~T}$ were incubated at 6 to $8^{\circ} \mathrm{C}$ in $250 \mathrm{l}$ circular tanks with water flow $\left(21 \mathrm{~min}^{-1}\right)$ and aeration. Light intensity was 300 to 400 lux and photoperiod was $24 \mathrm{~h}$. Dissolved oxygen and temperature were monitored daily, and dead eggs were siphoned out. The hatching rate ranged between 85 and $92 \%$ among different egg batches. When nearly $100 \%$ of the surviving eggs had hatched, larvae were transferred to $500 \mathrm{l}$ larval rearing tanks kept at 10 to $12^{\circ} \mathrm{C}$. Larval cod from $3 \mathrm{Ps}$ and $4 \mathrm{~T}$ were reared $3 \mathrm{mo}$ earlier than $4 \mathrm{X}$, but data from daily monitoring showed that temperature varied little between rearing periods (average temperature in ${ }^{\circ} \mathrm{C}, \pm \mathrm{SD}: 3 \mathrm{Ps} / 4 \mathrm{~T}, 11.05 \pm 0.21$; $4 \mathrm{X}, 11.22 \pm 0.14)$. During this period, they were fed with rotifers and Artemia using standard protocols (Brown et al. 2003). Briefly, larvae were fed rotifers from 2 to $42 \mathrm{~d}$ post-hatch (dph) and Artemia from 36 to $56 \mathrm{dph}$. Larvae were weaned to dry feed at $56 \mathrm{dph}$ and thereafter were fed ad libitum with pelleted feed (Dana commercial feed). Survival of larvae from hatching to weaning was about $8 \%$. After weaning, the juveniles were size graded 4 to 5 times into small, medium, and large to reduce cannibalism using a standard manual grader and all the graded fish were kept separately until the experiment was started.

Experimental set up. Six month old cod were held in three $500 \mathrm{ltanks}$ at 10 to $12^{\circ} \mathrm{C}$ for a period of $2 \mathrm{wk}$ prior to the experiment. To set up the temperature treatments, 90 fish (average tank biomass $1300 \mathrm{~g}$ [range: 7.99 to $33.26 \mathrm{~g}$; median: $14.8 \mathrm{~g}$ ] for $4 \mathrm{~T}_{;} 1100 \mathrm{~g}$ [range: 7.5 to $28.8 \mathrm{~g}$; median: $12.55 \mathrm{~g}$ ] for $3 \mathrm{Ps}_{\text {; }}$ and $1620 \mathrm{~g}$ [range: 7.34 to $37.81 \mathrm{~g}$; median: $15.63 \mathrm{~g}$ ] for $4 \mathrm{X}$ ) were placed in 1 of 12 tanks ( 2 treatments, 3 populations, 2 replicates). Juvenile cod were sampled from graded stocks of small, medium, and large fish in the proportion of their relative abundance in the holding tanks. All the experimental tanks were supplied with aerated seawater at a flow rate of 4 to $51 \mathrm{~min}^{-1}$. There were 2 temperature treatments: 10 to $12^{\circ} \mathrm{C}$ (high temperature $[\mathrm{HT}]$, in ${ }^{\circ} \mathrm{C}, \pm \mathrm{SD}: 4 \mathrm{X}, 10.92 \pm 0.36 ; 4 \mathrm{~T}, 11.03 \pm 0.23 ; 3 \mathrm{Ps}$, $11.02 \pm 0.26$ ) and 6 to $8^{\circ} \mathrm{C}$ (low temperature [LT], in ${ }^{\circ} \mathrm{C}$, $\pm \mathrm{SD}): 4 \mathrm{X}, 6.73 \pm 0.33 ; 4 \mathrm{~T}, 6.67 \pm 0.27 ; 3 \mathrm{Ps}, 6.7 \pm 0.24)$. These water temperatures were chosen to represent the temperatures that $4 \mathrm{X}, 4 \mathrm{~T}$, and 3Ps juveniles would experience in the wild. For LT treatments, temperature was gradually reduced to $6^{\circ} \mathrm{C}$ over a period of $3 \mathrm{~d}$, and then all 3Ps, 4X, and $4 \mathrm{~T}$ juveniles were acclimated to this LT for a period of $2 \mathrm{wk}$ before the start of the experiment. Fluorescent tubes provided lighting, and the light regimen was adjusted as 12:12 h dark:light cycle, at a light intensity of 300 lux. Artificial dawn and dusk were maintained by low wattage lamps providing 50 lux intensity and were controlled by a timer. The temperature, dissolved oxygen concentrations, and mortalities were recorded daily for each tank.

All juveniles were fed with formulated diet at a ration of $2 \%$ of body weight. This ration was selected based on previous field studies on both Age 0 and 1 wild cod (Grant \& Brown 1998) and on the feed manufacturer's recommendation (Dana Feed). All tanks were hand fed twice daily with formulated pellet to satiation, or until the ration was finished. The weight of food eaten by the group of fish in each tank was recorded. The feed was delivered as 10 to 20 pellets at a time and consumption of the pellets by the fish in each tank was closely monitored. The point of satiation was determined when approximately half of the pellets that were fed to the fish sank to the bottom and were left uneaten. Thereafter, another 5 to 10 pellets were distributed to each tank to ensure satiation was achieved. All mortalities, if any, were removed daily, and the numbers, condition, and appearance of the fish were recorded. All fish were accounted for during the experimental period of $15 \mathrm{wk}$.

Growth measurements. Growth measurements were taken once every $3 \mathrm{wk}$ to monitor fish performance in different treatments. Fish were not fed $24 \mathrm{~h}$ before sampling. All the fish were anesthetized using tricaine methanesulphonate (MS-222) before sampling. Total biomass of all 90 fish in each tank (to the nearest $1 \mathrm{~g}$ ) was measured to calculate the growth rate. Standard length $\left(L_{\mathrm{S}}\right.$, nearest $\left.0.1 \mathrm{~cm}\right)$, total length $\left(L_{\mathrm{T}}\right.$, nearest $\left.0.1 \mathrm{~cm}\right)$, and wet weight (nearest $0.01 \mathrm{~g}$ ) of 25 fish were also measured. All fish were returned to the respective tanks after measurements. None of the mortalities was related to sampling, as no mortalities were recorded within $2 \mathrm{~d}$ of the sampling. Using total biomass, the weight specific growth rate (SGR) of each tank was determined using the following relationship:

$$
\mathrm{SGR}=\left\{\left[\ln \left(W_{\mathrm{f}}\right)-\ln \left(W_{\mathrm{i}}\right)\right] t^{-1}\right\} \times 100
$$

where $W_{\mathrm{f}}$ is the mean final wet biomass $(\mathrm{g}), W_{\mathrm{i}}$ is the mean initial wet biomass $(\mathrm{g})$, and $t$ is the duration between initial and final sampling (days).

FCE was determined using the following relationship:

$$
\mathrm{FCE}=W_{\mathrm{g}} \times W_{\mathrm{fe}}^{-1}
$$

where $W_{\mathrm{g}}$ is the weight gain of fish in each tank which is calculated from the total biomass and $W_{\mathrm{fe}}$ is the 
weight of food eaten by fish in each tank over a specific time period.

Relative condition factor $\left(K_{\mathrm{n}}\right)$ was calculated using methods described by Craig et al. (2005). Leastsquares regression was performed on log-transformed total length and wet weight measurements to determine the length-weight relationship for each population by treatment (temperature). The $K_{\mathrm{n}}$ equation used was:

$$
K_{\mathrm{n}}=W /\left(\mathrm{a} \times L_{\mathrm{T}}{ }^{n}\right)
$$

where $W$ is wet weight $(\mathrm{kg}), L_{\mathrm{T}}$ is total length (mm), $a$ is the exponential form of the intercept, and $n$ represents the slope of the logarithmic length-weight equation.

Data analyses. A repeated measures ANOVA was performed to determine differences in SGR, FCE, $L_{\mathrm{S}}$, and $K_{\mathrm{n}}$ among the 3 populations (GLM procedure, SPSS 13.0 for Windows). The initial mean wet mass or length was used as a covariable in the model to account for the differences in initial wet mass and length among the 3 populations. The test was performed with population and temperature as explanatory variables with interactions in the model to determine the effect of temperature on differences among the $3 \mathrm{Ps}, 4 \mathrm{~T}$, and $4 \mathrm{X}$ populations. Thereafter the same model was used to test for differences within treatment for SGR, FCE, $L_{\mathrm{S}}$, and $K_{\mathrm{n}}$ among $3 \mathrm{Ps}, 4 \mathrm{~T}$, and $4 \mathrm{X}$ with initial mean wet mass or length as the covariable. Multiple comparisons of population means for the above variables were made using a Bonferroni correction. Significance level was set at 0.05 for all the tests. To examine population differences within the $15 \mathrm{wk}$ period, the data for SGR, FCE, $L_{\mathrm{S}}$, and $K_{\mathrm{n}}$ were also tested using ANOVAs (generalized linear model, GENMOD procedure, SAS 1988). The data for survival were also tested among the populations over the experimental period with logistic regression for comparison with the repeated measures analysis. Residuals were examined for the assumption of independence, homogeneity, and normality (Sokal \& Rohlf 1995).

\section{RESULTS}

\section{Initial data}

Juvenile cod from 3Ps were significantly smaller (standard length and wet mass) at age than the juveniles from $4 \mathrm{~T}$ and $4 \mathrm{X}$ at the start of the experiment (Table 1). No significant differences were found in standard length and $K_{\mathrm{n}}$ between $4 \mathrm{~T}$ and $4 \mathrm{X}_{\text {; however, }}$ juveniles from $4 \mathrm{X}$ had significantly higher wet mass than the $4 \mathrm{~T}$ juveniles at the start of the experiment (Table 1). Both $4 \mathrm{~T}$ and $4 \mathrm{X}$ juveniles were in better con-
Table 1. Mean $( \pm \mathrm{SE})$ wet mass, standard length $\left(L_{\mathrm{S}}\right)$, and relative condition factor $\left(K_{\mathrm{n}}\right)$ of $0+$ juvenile cod from populations from NAFO divisions $4 \mathrm{~T}, 3 \mathrm{Ps}$, and $4 \mathrm{X}$ at the start of the experiment. Significant differences are indicated by different superscript letters

\begin{tabular}{|lccl|}
\hline Population & $\begin{array}{c}\text { Wet mass } \\
(\mathrm{g})\end{array}$ & $\begin{array}{c}L_{\mathrm{S}} \\
(\mathrm{cm})\end{array}$ & $K_{\mathrm{n}}$ \\
\hline $3 \mathrm{Ps}$ & $12.80 \pm 0.24^{\mathrm{a}}$ & $10.08 \pm 0.056^{\mathrm{k}}$ & $0.96 \pm 0.013^{\mathrm{x}}$ \\
$4 \mathrm{~T}$ & $15.46 \pm 0.05^{\mathrm{b}}$ & $11.3 \pm 0.27^{1}$ & $1.02 \pm 0.012^{\mathrm{y}}$ \\
$4 \mathrm{X}$ & $18.08 \pm 0.03^{\mathrm{c}}$ & $11.3 \pm 0.10^{1}$ & $1.02 \pm 0.033^{\mathrm{y}}$ \\
\hline
\end{tabular}

dition than 3Ps juveniles at the start of the experiment (Table 1).

\section{SGR and FCE}

SGR was not significantly different among 3Ps, 4T, and $4 \mathrm{X}$ juveniles in both HT and LT $\left(F_{[2,60]}=2.827, \mathrm{p}=\right.$ 0.15 ) over the experimental period (repeated measures). However, 3Ps juveniles had a higher SGR than both $4 \mathrm{~T}$ and $4 \mathrm{X}$ cod during the first $3 \mathrm{wk}\left(\chi_{[1,8]}^{2}=8.89\right.$, $\mathrm{p}=0.0029$; ANOVA) and remained significantly different from $4 \mathrm{X}$ individuals until the end of the 6 th week in both HT and LT (Fig. 2). The SGR of 3Ps, 4T, and $4 \mathrm{X}$ juveniles was significantly higher in HT than in LT $\left(F_{[2,60]}=30.51, \mathrm{p}=0.003\right)$. The SGR of 3Ps juveniles in the HT treatment was $36 \%$ higher than in its corresponding LT treatment, while SGR for $4 \mathrm{~T}$ and $4 \mathrm{X}$ juveniles differed only 13 and $22 \%$ in their respective treatments. Overall, there were no significant differences in SGR among populations at any given temperature $\left(F_{[2,60]}=1.777, \mathrm{p}=0.26\right)$. However, the SGR of 3Ps juveniles was 21 and $50 \%$ higher in the HT and 3 and $37 \%$ higher in the LT than the $4 \mathrm{~T}$ and $4 \mathrm{X}$ juveniles, respectively. Similarly, 4T had 24 and $33 \%$ higher SGR than $4 \mathrm{X}$ in HT and LT, respectively. FCE was not significantly different among $3 \mathrm{Ps}, 4 \mathrm{~T}$, and $4 \mathrm{X}$ juveniles in both HT and LT $\left(F_{[2,60]}, \mathrm{p}=0.68\right)$. However, FCE differed among populations during certain periods (LT), but results were inconsistent (interaction term $\chi_{[2,30]}^{2}=$ $36.54, \mathrm{p}=0.0001$; ANOVA) and there was no apparent pattern.

\section{Standard length}

Our repeated measures analysis showed that $L_{\mathrm{S}}$ of juvenile cod did not differ among the 3 populations in either the HT $\left(F_{[2,30]}=0.188, \mathrm{p}=0.84\right)$ or LT $\left(F_{[2,30]}=\right.$ 1.959, $\mathrm{p}=0.34$; Fig. 3 ) treatments. However, $L_{\mathrm{S}}$ of some populations at HT differed during certain weeks (inter- 


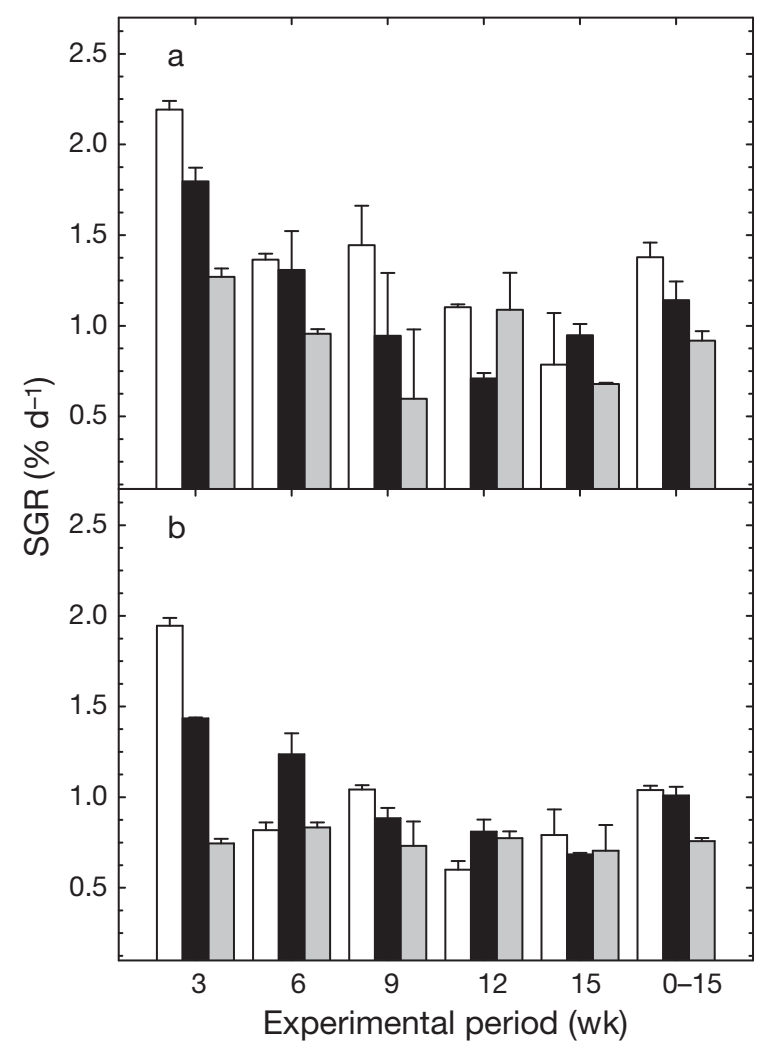

Fig. 2. Specific growth rate $\left(\mathrm{SGR}_{1} \pm \mathrm{SD}\right)$ for $0+$ cod juveniles from populations 3Ps $(\square), 4 \mathrm{~T}(\square)$, and $4 \mathrm{X}(\square)$ at (a) high temperature $\left(10\right.$ to $\left.12^{\circ} \mathrm{C}\right)$ and (b) low temperature $\left(6\right.$ to $\left.8^{\circ} \mathrm{C}\right)$ during the 15 wk experimental period. Data on overall SGR during the experiment are also included for each treatment. $\mathrm{N}=2$

action term $\chi^{2}{ }_{[2,30]}=30.26, \mathrm{p}=0.0008$; ANOVA); no overall pattern was apparent. Within HT and LT, juvenile cod increased in $L_{\mathrm{S}}$ over the experimental period, but there were no significant differences among populations $\left(F_{[2,30]}=0.740, \mathrm{p}=0.52\right)$. However, juvenile cod from each population grew $\left(L_{\mathrm{S}}\right)$ significantly more in HT than in $\operatorname{LT}\left(F_{[2,60]}=25.04, \mathrm{p}=0.002\right)$.

\section{$K_{\mathrm{n}}$ and survival}

$K_{\mathrm{n}}$ was not significantly different among $3 \mathrm{Ps}_{\mathrm{s}}, 4 \mathrm{~T}$, and $4 \mathrm{X}$ populations in $\mathrm{HT}\left(F_{[2,30]}=7.26, \mathrm{p}=0.121\right)$. Significant differences in $K_{\mathrm{n}}$ were present within populations in certain weeks in both HT and LT during the experimental period with no obvious pattern overall (interaction term $\chi_{[2,60]}^{2}=26.58, p=0.003$ ). Survival in the northernmost 3Ps population (176/180 at HT, 177/180 at LT) was significantly higher than in $4 \mathrm{~T}$ $\left(162 / 180\right.$ at HT, $175 / 180$ at $\mathrm{LT}_{i} \chi_{[2,48]}^{2}=9.22, \mathrm{p}=$ $0.0021)$, and $4 \mathrm{~T}$ had significantly higher survival than $4 \mathrm{X}\left(115 / 180\right.$ at $\mathrm{HT}, 145 / 180$ at $\mathrm{LT}_{i} \chi^{2}{ }_{[2,48]}=62.73, \mathrm{p}=$

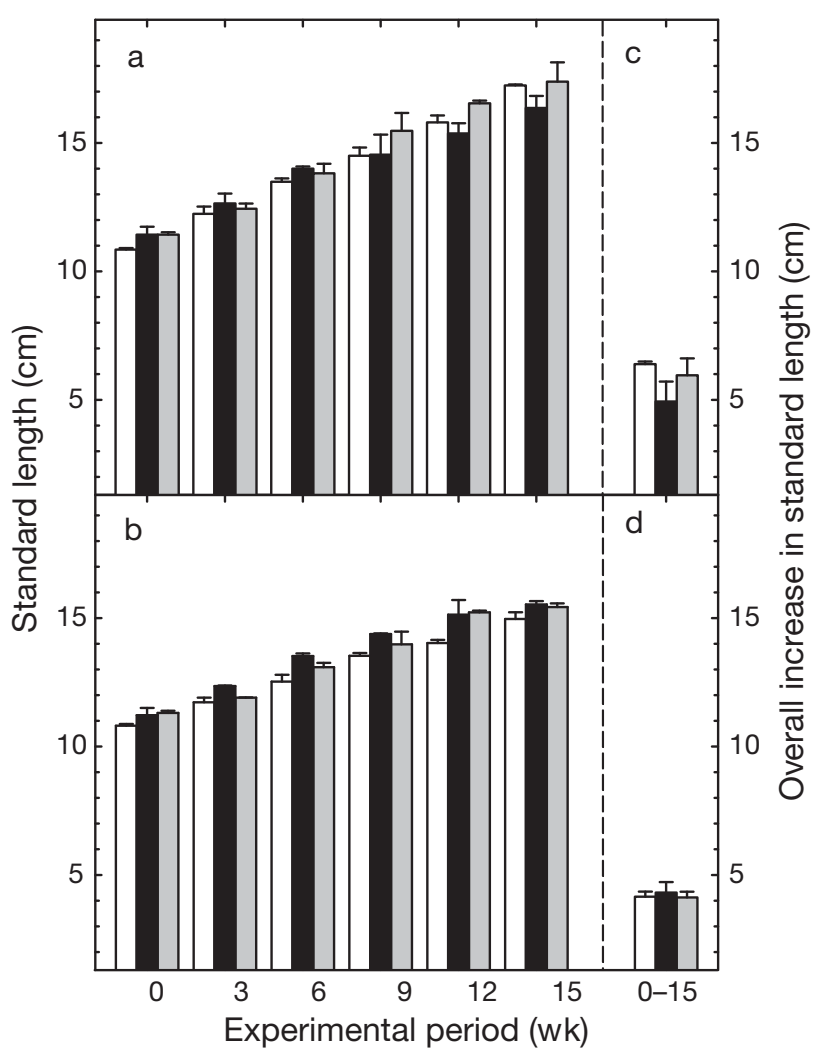

Fig. 3. Mean standard length $( \pm \mathrm{SD})$ for $0+$ cod juveniles from populations 3Ps $(\square), 4 \mathrm{~T}(\square)$ and $4 \mathrm{X}(\square)$ at (a) high temperature (HT) and (b) low temperature (LT) during the 15 wk experimental period. $(\mathrm{c}, \mathrm{d})$ Overall increase in standard length $( \pm \mathrm{SD})$ for $0+$ cod juveniles from $3 \mathrm{Ps}, 4 \mathrm{~T}$, and $4 \mathrm{X}$ at HT and LT, respectively, during the $15 \mathrm{wk}$ experiment for each treatment.

$$
\mathrm{N}=2
$$

0.001) in both HT and LT. All populations had significantly higher survival in LT than in HT (all $\mathrm{p}<0.0077$; Fig. 4).

\section{Reaction norm}

The norm of reaction of SGR, or phenotypic plasticity of SGR, for the HT and LT treatments of cod juveniles from 3 populations did not cross over (Fig. 5a). The 3Ps juveniles had a higher elevation reaction norm for SGR than the other 2 populations in both treatments. The reaction norms of $3 \mathrm{Ps}, 4 \mathrm{~T}$, and $4 \mathrm{X}$ also resulted in different slopes. Reaction norms for survival among the 3 cod populations did not cross with any apparent differences in the slope of the survival of 3Ps between HT and LT. However, both $4 \mathrm{~T}$ and $4 \mathrm{X}$ cod juveniles showed a higher elevation reaction norm at LT (Fig. 5b). Both 3Ps and 4T juveniles had elevated reaction norms for survival compared to $4 \mathrm{X}$ juveniles in both temperatures. 


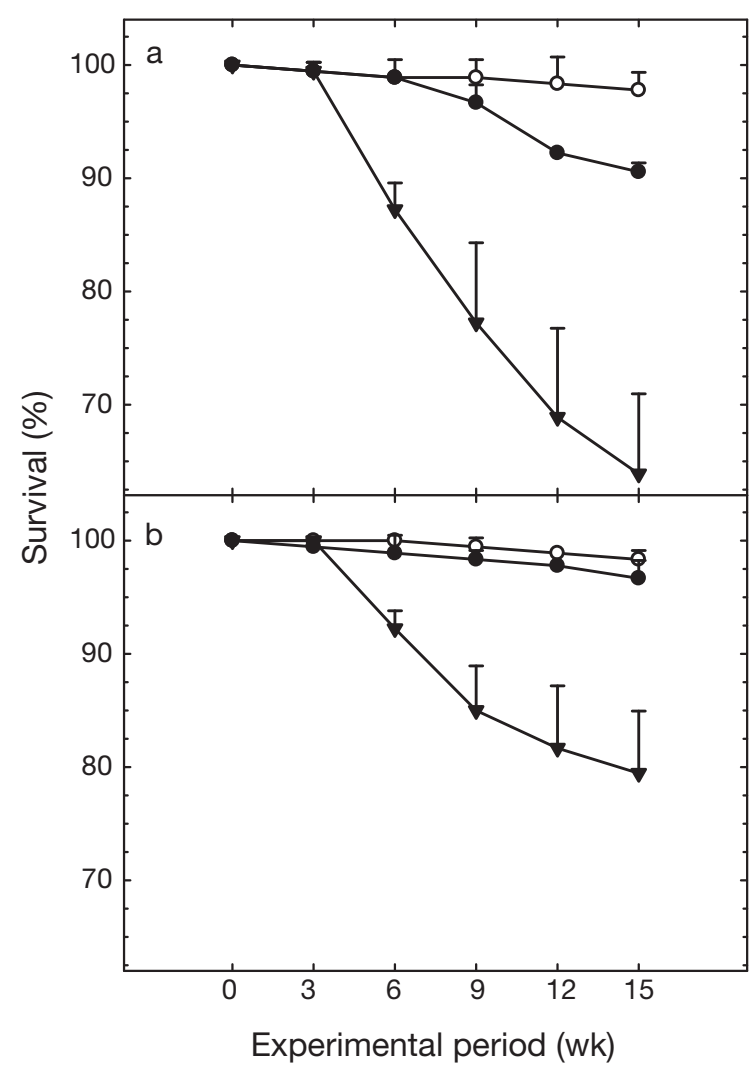

Fig. 4. Mean survival $( \pm \mathrm{SD})$ for $0+$ cod juveniles from populations 3Ps (O), 4T (•), and $4 \mathrm{X}(\mathbf{\nabla})$ at (a) high temperature (10 to $\left.12^{\circ} \mathrm{C}\right)$ and (b) low temperature $\left(6\right.$ to $\left.8^{\circ} \mathrm{C}\right)$ during the $15 \mathrm{wk}$ experimental period. $\mathrm{N}=2$

\section{DISCUSSION}

Several studies suggested a higher capacity for growth of adult (Brander 1995), juvenile (Suthers \& Sundby 1996), and larval cod (Hunt von Herbing \& Boutilier 1996, Purchase \& Brown 2000a) in higher latitude waters. However, no significant difference in SGR was found among juvenile cod from 3Ps, 4T, and $4 \mathrm{X}$ reared at HT or LT in our study. Purchase \& Brown (2000b) reported no significant differences in SGR between Gulf of Maine and Grand Banks juvenile cod. Although not significantly different $(p=0.074)$, the overall SGR of 3Ps juveniles, the most northern of the 3 populations, had higher overall SGR than $4 \mathrm{~T}$ (in HT) and 4X (in HT and LT) juveniles. Smaller fish tend to have higher SGR, which may partly explain why the 3 Ps juveniles had higher growth rates than $4 \mathrm{~T}$ and $4 \mathrm{X}$ juveniles. However, $4 \mathrm{~T}$ juveniles, which were a similar size to $4 \mathrm{X}$ juveniles at the start of the experiment, had better SGR than $4 \mathrm{X}$ juveniles. Nevertheless, 3Ps juveniles were smaller than $4 \mathrm{X}$ and $4 \mathrm{~T}$ juveniles at the start of the experiment, but were similar in size to $4 \mathrm{X}$ and larger than $4 \mathrm{~T}$ at the end of the experiment. Thus, the
3Ps (and 4T) juveniles supported the trend of higher capacity for growth when provided with favorable temperatures.

In temperature-controlled studies, faster growth rates at higher latitudes have also been found in largemouth bass Micropterus salmoides (Williamson \& Carmichael 1990), Atlantic salmon Salmo salar (Nicieza et al. 1994), and striped bass (Conover et al. 1997). Seasonality, as measured by the length of the growing season, has a significant evolutionary effect on growth rates whereby intrinsic rates of growth tend to be greater in populations adapted to higher latitudes (Conover \& Schultz 1995). Length of the growing season is the principal assumption underlying the CnGV hypothesis. Laboratory experiments with larval striped bass, American shad, and Atlantic silverside have shown that larval and juvenile fish from northern populations have a higher inherent capacity for growth than their counterparts from southern populations (Conover 1990, Conover et al. 1997). In our study, 3Ps juveniles were significantly smaller in length and wet mass than $4 \mathrm{~T}$ and $4 \mathrm{X}$ at the start of the experiment. However, no significant difference in standard length or wet mass among the 3 populations at the end of the experiment indicates a trend toward faster growth of cod juveniles from the most northern population. Our northernmost cod population grew 20 or $50 \%$ faster at

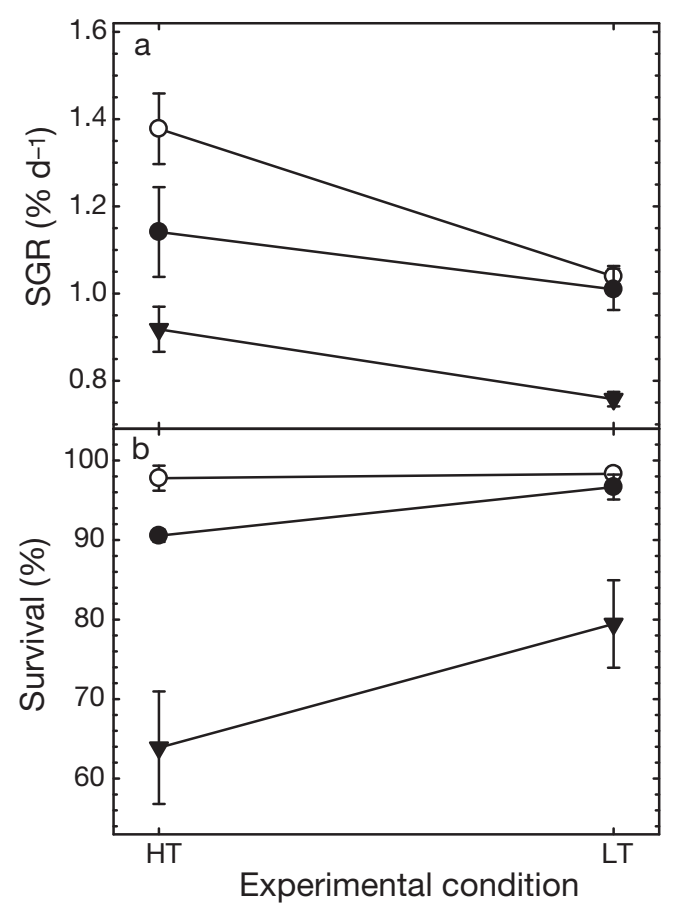

Fig. 5. Reaction norms for (a) specific growth rate (SGR) and (b) survival of 3Ps $(0), 4 \mathrm{~T}(\boldsymbol{\bullet})$, and $4 \mathrm{X}(\boldsymbol{\nabla})$ of $0+$ juvenile cod reared under high and low temperature (HT and LT, respectively) $( \pm \mathrm{SD})$ during the $15 \mathrm{wk}$ experimental period 
HT, and $3 \%$ or $37 \%$ faster at LT, than the 2 southern populations. The narrow latitudinal and temperature differences during the growing season between 3Ps and $4 \mathrm{~T}\left( \pm 1^{\circ} \mathrm{C}\right)$ may have contributed toward lowering the difference in SGRs of these juveniles. However, $4 \mathrm{X}$ juveniles experience approximately 6 to $7^{\circ} \mathrm{C}$ higher temperature than the 3Ps and $4 \mathrm{~T}$ juveniles during the same life stage (DFO 2006). Thus having a longer growing season during this life stage did not translate into better growth of $4 \mathrm{X}$ juveniles.

Fish populations from higher latitudes should have improved FCEs to exploit the shorter growing season (Nicieza et al. 1994). Northern fish populations of Atlantic silverside (Present \& Conover 1992) and Atlantic salmon (Nicieza et al. 1994) have a higher FCE than southern populations. Further evidence in support of a CnGV in FCE was reported in juvenile turbot (Imsland et al. 2000) and Atlantic halibut Hippoglossus hippoglossus (Jonassen et al. 2000). However, the FCE for 3Ps, 4T, and $4 \mathrm{X}$ juveniles in the HT was not significantly different in our experiment.

$K_{\mathrm{n}}$ is a good predictor of the nutritional status of fish (Craig et al. 2005). Although we found that $K_{\mathrm{n}}$ of 3Ps juveniles was lower than that of both $4 \mathrm{~T}$ and $4 \mathrm{X}$ populations at the beginning of the experiment, no differences were detected among populations at the end of the experiment. This suggests that wet mass and length in juveniles of the 3 populations did not increase allometrically even though food was not a limiting factor.

The northern population (3Ps) had significantly higher survival than $4 \mathrm{~T}$ and $4 \mathrm{X}$ populations in $\mathrm{HT}$ and LT. Faster growth during the relatively shorter growing season in high latitude populations is well documented (CnGV) (Conover \& Present 1990, Conover \& Schultz 1995, Hunt von Herbing \& Boutilier 1996, Conover et al. 1997). The increase in growth rate with HT is important due to the size dependent mortality during winter (Conover \& Present 1990). Reaction norm analysis also showed possible genetic differences in survival among the 3 populations. The difference in survival between 3Ps and $4 \mathrm{~T}$ was not as pronounced as the differences between $3 \mathrm{Ps}$ and $4 \mathrm{X}$ or between $4 \mathrm{~T}$ and $4 \mathrm{X}$; however, this could be due to the narrow latitudinal differences between 3Ps and $4 \mathrm{~T}$ populations. Apart from this, these $3 \mathrm{cod}$ populations show support for $\mathrm{CnGV}$ in survival. In general, faster growing fish have better survival rates than slow growing fish assuming that no major predatory mortalities occur (Ottersen \& Loeng 2000). In our experiment, cod juveniles from all populations reared in LT had lower growth rates but better survival than the juveniles from $\mathrm{HT}$, and the reason for this is unclear.

Although we found no major differences in SGR among 3 cod populations, similar studies showed evi- dence for CnGV and significant differences in SGR and morphological indices (Marcil et al. 2006a,b, Hutchings et al. 2007). Earlier studies in our laboratory showed that similar-sized cultured juvenile cod from 4X and 3L differed significantly in their body shape and revealed CnGV (Marcil et al. 2006a). In the present study, the juveniles initially differed in length, weight, and $K_{\mathrm{n}}$, but these differences were no longer apparent at the end of the experiment. Similarly, Hutchings et al. (2007) showed significant differences in growth and survival among these populations during the larval stage. The larvae used by Hutchings et al. (2007) and juveniles used in our study were obtained from the same egg batches. Thus, it appears that morphological differences apparent early in ontogeny among these populations eventually disappear as individuals continue to develop. Testing for $\mathrm{CnGV}$ on growth differences in older juveniles may obscure true population differences, possibly due to the relatively smaller growth potential of older juveniles than of young juveniles and larval stages. Alternatively, phenotypic traits may change more than once during the development of that particular individual or may be entirely stage specific (Stearns 1989). It is therefore possible that the use of smaller juveniles for our study would have yielded more prominent population differences in growth and FCE among these 3 cod populations.

Information on phenotypic variability in juvenile cod across natural environments is limited. The analysis of crossing norms in our study provides a means of determining the degree of environmental and genetic influence on particular phenotypes. Prominent differences among the reaction norms of populations suggest a genetic influence, whereas crossing reaction norms indicate an interaction between environment and genotype (Stearns 1989). Crossing reaction norms help to determine the heritability of the variation in a phenotype. If reaction norms do not cross for fitness related traits, then the phenotypic value of that reaction norm would be adaptive in all the environmental conditions (Stearns 1989). In our experiment, the SGR reaction norms of $3 \mathrm{Ps}, 4 \mathrm{~T}$, and $4 \mathrm{X}$ varied but did not intersect. These data indicate there are possible genetic differences among populations, but there was no genotype: environment interaction and the phenotypic value of the SGR reaction norm for 3Ps was higher than those for $4 \mathrm{~T}$ and $4 \mathrm{X}$ at both temperatures.

The reaction norms indicated that the growth rates of cod juveniles from the 3 populations may be influenced more by the genotype than the environment. Although reaction norm analysis shows genetic differences in SGR among Atlantic cod juveniles from the 3 NAFO subdivisions, statistical analysis showed no significant difference in SGR among these 3 cod popula- 
tions. The statistical analysis that we performed was robust though conservative (Bonferroni corrections), which could have masked a true difference in SGR of cod juveniles among these 3 populations. A less conservative ANOVA test showed significant differences in SGR among the cod juveniles of the 3 populations. In addition to this potential for a Type II error, our results may not support the hypothesis of $\mathrm{CnGV}$ in growth because of the age and size of the juveniles used in our experiments; support for CnGV was found in a previous study on larvae from the same egg batches used in our study. Alternatively, sampling additional populations with a larger latitudinal variation may be useful. Research on how phenotypic differences among populations from different latitudes differ with ontogeny would provide more insight into the CnGV.

Acknowledgements. We thank A. Kellett and staff at the Joe Brown Aquatic Research Building, Memorial University of Newfoundland, and J. Eddigton at the Aquatron Laboratory, Dalhousie University for their technical help. We appreciate the critical comments from 2 anonymous reviewers and Dr. B. Laurel on the earlier version of this manuscript. Statistical advice from Dr. D. Schneider is greatly appreciated. The work was supported by a Strategic Grant awarded to J.A.B. by the Natural Sciences and Engineering Research Council (NSERC) of Canada. The research protocol was approved by Memorial University's Committee on Animal Welfare, in accordance with the guidelines provided by the Canadian Council on Animal Care.

\section{LITERATURE CITED}

Bentzen P, Taggart CT, Ruzzante DE, Cook D (1996) Microsatellite polymorphism and the population structure of cod (Gadus morhua) in the northwest Atlantic. Can J Fish Aquat Sci 53:2706-2721

Bradbury IR, Laurel B, Robichaud D, Rose GA, Snelgrove PVR, Gregory B, Cote D (2008) Discrete spatial dynamics and essential habitat of coastal cod populations: conservation and management implications. Fish Res 91:299-309

Brander KM (1994) Patterns of distribution, spawning, and growth in north Atlantic cod: the utility of inter-regional comparisons. ICES Mar Sci Symp 198:406-413

Brander KM (1995) The effect of temperature on growth of Atlantic cod (Gadus morhua L.). ICES J Mar Sci 52:1-10

Brown JA, Minkoff G, Puvanendran V (2003) Larviculture of Atlantic cod (Gadus morhua): progress, protocol and problems. Aquaculture 227:357-372

Comeau LA, Campana SE, Chouinard GA (2002) Timing of Atlantic cod (Gadus morhua L.) seasonal migrations in the southern Gulf of St. Lawrence: interannnual variability and proximate control. ICES J Mar Sci 59:333-351

Conover DO (1990) The relation between capacity for growth and length of growing season: evidence for and implications of counter-gradient variation. Trans Am Fish Soc 119: 416-430

Conover DO, Present TMC (1990) Countergradient variation in growth rate: compensation for length of the growing season among Atlantic silversides from different latitudes. Oecologia 83:316-324
Conover DO, Schultz ET (1995) Phenotypic similarity and the evolutionary significance of counter-gradient variation. Trends Ecol Evol 10:248-252

Conover DO, Brown JJ, Ehtisham A (1997) Countergradient variation in growth of young striped bass (Morone saxatilis) from different latitudes. Can J Fish Aquat Sci 54: 2401-2409

Craig JM, Thomas MV, Nichols SJ (2005) Length-weight relationship and a relative condition factor equation for lake sturgeon (Acipenser fulvescens) from the St Clair River system (Michigan, USA). J Appl Ichthyol 21:81-85

DFO (2006) Marine environmental data services, Atlantic Zone Monitoring Program, Fisheries and Oceans Canada. Accessed 8 June 2007. www.meds-sdmm.dfo-mpo.gc.ca/ zmp/main_zmp_e.html

Grant SM, Brown JA (1998) Diel foraging cycles and interactions among juvenile Atlantic cod (Gadus morhua) at a nearshore site in Newfoundland. Can J Fish Aquat Sci 55:1307-1316

Hunt von Herbing I, Boutilier RG (1996) Activity and metabolism of larval Atlantic cod (Gadus morhua) from Scotian Shelf and Newfoundland source populations. PSZN I: Mar Ecol 124:607-617

Hutchings JA, Myers RA, Lilly GR (1993) Geographic variation in the spawning of Atlantic cod, Gadus morhua, in the northwest Atlantic. Can J Fish Aquat Sci 50:2457-2467

> Hutchings JA, Swain DP, Rowe S, Eddington JD, Puvanendran V, Brown JA (2007) Genetic variation in life-history reaction norms in a marine fish. Proc R Soc Lond B Biol Sci 274:1693-1699

Imsland AK, Foss A, Nævdal G, Cross T, Bonga SW, Ham EV, Stefánsson SO (2000) Countergradient variation in growth and food conversion efficiency of juvenile turbot. J Fish Biol 57:1213-1226

Jonassen TM, Imsland AK, Fitzgerald R, Bonga SW and others (2000) Geographic variation in growth and food conversion efficiency of juvenile Atlantic halibut related to latitude. J Fish Biol 56:279-294

> Jónsdóttir ÓDB, Daníelsdóttir AK, Nævdal G (2001) Genetic differentiation among Atlantic cod (Gadus morhua L.) in Icelandic waters: temporal stability. ICES J Mar Sci 58: $114-122$

> Kjesbu OS, Solemdal P, Bratland P, Fonn M (1996) Variation in annual egg production in individual captive Atlantic cod (Gadus morhua). Can J Fish Aquat Sci 53:610-662

> Knutsen H, Olsen EM, Ciannelli L, Espeland SH and others (2007) Egg distribution, bottom topography and smallscale cod population structure in a coastal marine system. Mar Ecol Prog Ser 333:249-255

Lawson GL, Rose GA (2000) Seasonal distribution and movements of coastal cod (Gadus morhua L.) in Placentia Bay, Newfoundland. Fish Res 49:61-75

Marcil J (2004) Genetic and environmental components of phenotypic variation in body shape among populations of Atlantic cod (Gadus morhua). MSc thesis, Dalhousie University, Halifax, Nova Scotia

> Marcil J, Swain DP, Hutchings JA (2006a) Countergradient variation in body shape between two populations of Atlantic cod (Gadus morhua). Proc R Soc Lond B Biol Sci 273:217-223

Marcil J, Swain DP, Hutchings JA (2006b) Genetic and environmental components of phenotypic variation in body shape among populations of Atlantic cod (Gadus morhua L.). Biol J Linn Soc 88:351-365

> Nicieza AG, Reiriz L, Brana F (1994) Variation in digestive performance between geographically disjunct populations of Atlantic salmon: countergradient in passage time and digestion rate. Oecologia 99:243-251 
Otterlei E, Nyhammer G, Folkvord A, Steffansson SO (1999) Temperature- and size-dependent growth of larval and juvenile Atlantic cod (Gadus morhua): a comparative study of Norwegian coastal cod and northeast Arctic cod. Can J Fish Aquat Sci 56:2099-2111

Ottersen G, Loeng H (2000) Covariability in early growth and year-class strength of Barents Sea cod, haddock, and herring: the environmental link. ICES J Mar Sci 57:339-348

Present TMC, Conover DO (1992) Physiological basis of latitudinal growth differences in Menidia menidia: variation in consumption of efficiency? Funct Ecol 6:23-31

Purchase CF, Brown JA (2000a) Interpopulation differences in growth rates and food conversion efficiencies of young Grand Banks and Gulf of Maine Atlantic cod (Gadus morhua). Can J Fish Aquat Sci 57:2223-2229

Purchase CF, Brown JA (2000b) Stock-specific changes in specific growth rates, food conversion efficiencies, and energy allocation in response to temperature change in juvenile Atlantic cod. J Fish Biol 56:36-52

Ricklefs RE, Wikelski M (2002) The physiology/life-history nexus. Trends Ecol Evol 17:462-468

Ruzzante DE, Taggart CT, Cook D, Goddard SV (1997) Genetic differentiation between inshore and offshore Atlantic cod (Gadus morhua) off Newfoundland: a test and evidence of temporal stability. Can J Fish Aquat Sci 54:2700-2708

Ruzzante DE, Taggart CT, Cook D (1999) A review of the evidence for genetic structure of cod (Gadus morhua) populations in the NW Atlantic and population affinities of larval cod off Newfoundland and the Gulf of St. Lawrence. Fish Res 43:79-97

Salvanes AGV, Skjæraasen JE, Nilsen T (2004) Sub-populations of coastal cod with different behaviour and life-

Editorial responsibility: Hans Heinrich Janssen, Oldendorf/Luhe, Germany history strategies. Mar Ecol Prog Ser 267:241-251

SAS (1988) SAS/STAT release 6.03. SAS Institute, Cary, NC

Scott WB, Scott MG (1988) Atlantic fishes of Canada. Can Bull Fish Aquat Sci 219

Sokal RR, Rohlf JJ (1995) Biometry: the principles and practice of statistics in biological research, 3rd edn. Freeman, New York

Stearns SC (1989) The evolutionary significance of phenotypic plasticity. BioScience 39:436-445

Suthers IM, Sundby S (1996) Role of the midnight sun: comparative growth of pelagic juvenile cod (Gadus morhua) form the Arcto-Norwegian and a Nova Scotian stock. ICES J Mar Sci 53:827-836

Svåsand T, Jorstad KE, Kjesbu OS (1996) Differences in growth performance between Arcto-Norwegian and coastal cod reared under identical conditions. J Fish Biol 49:108-119

Taggart CT, Penny P, Barrowman N, George C (1995) The 1954-1993 Newfoundland cod-tagging database: statistical summaries and spatial-temporal distributions. Can Tech Rep Fish Aquat Sci No 2042

Templeman W (1981) Vertebral numbers in Atlantic cod, Gadus morhua, of the Newfoundland and adjacent area, 1947-71, and their use for delineating cod stocks. J Northwest Atl Fish Sci 2:21-45

Williamson JH, Carmichael GJ (1990) An aquaculture evaluation of Florida, northern, and hybrid largemouth bass, Micropterus salmoides. Aquaculture 85:247-258

> Yamahira K, Kawajiri M, Takeshi K, Irie T (2007) Inter- and intra population variation in thermal reaction norms for growth rate: evolution of latitudinal compensation in ectotherms with a genetic constraint. Evolution 61: $1577-1589$

Submitted: November 26, 2007; Accepted: September 25, 2008 Proofs received from author(s): December 19, 2008 